\title{
A Systematic Method to the Formation of Career Orientation of Adolescents in Terms of Additional Education
}

\author{
Anastasia V. Mishina, Zilia M. Yavgildina, Nadegda V. Mishina, Olga G. Belomoeva
}

\begin{abstract}
The problem of the career orientation for adolescents in the context of their further education is caused by a number of circumstances. First of all, amid the demand by the state and society for creative professions, the younger generation has a superficial and disorienting idea of the nature and specificity of professional activity. In addition, the professional sphere of activity of an artist, a designer, a decorator is being improved and complicated, requiring a specialist to possess high information, computer, and art technologies. A purposeful acquaintance with future professions in the field of visual and spatial arts, the professional formation of such a specialist, starting from age of adolescence, is facilitated by a modern system of additional education with high potential. Proceeding from this, the indicated problem requires science to develop its theoretical and methodological foundations, a substantial technological base and appeal to innovative, developing, personality-oriented ways of organizing the educational process of an integrated type. Within the framework of this study, we dwell on the methodological foundations of the formation of career orientation and consider in more detail the systematic approach as fundamental.
\end{abstract}

As a result, we studied the concept of "career orientation", revealed the essence of the career orientation formation process in adolescents, which is carried out in close connection with other mental processes and personality traits. It was proved during the experiment that the use of a systematic approach and relevant principles contributes to more effective formation of career orientation for adolescents.

Keywords: art education, career orientation, the formation of career orientation, a systematic approach, principles, adolescents.

\section{INTRODUCTION}

The modern era of the rapid development of project culture, visualization tools, design, and computer technology requires the availability of creatively-minded and active professionals with relevant competencies in the field of visual and spatial arts $[1 ; 2]$. In this regard, the problem of the timely career orientation formation at adolescents in the field of visual and spatial arts in the context of additional education is becoming especially acute.

Such researchers as E.I. Bayramova, A.D. Sazonov, R.G. Salakhutdinov, and G.G. Solodov devoted their work to career orientation issues; they consider career orientation as an individual's ability to navigate in the social space, analyse problems, and make optimal decisions. Based on the study of different approaches to the determination of the concept

Revised Manuscript Received on November 08, 2019.

* Correspondence Author

Anastasia V. Mishina ${ }^{1}$, Zilia M. Yavgildina ${ }^{2}$, Nadegda V. Mishina ${ }^{1}$, Olga G. Belomoeva ${ }^{3}$

${ }^{1}$ Kazan Federal University,

${ }^{2}$ Kazan State Institute of Culture

${ }^{3}$ Mordovia National State Research University named after N.P. Ogarev "career orientation", we consider it as a state of awareness of a teenager's personality in the field of visual and spatial arts, including functions of various aspects: social, economic, psychological and pedagogical. The formation process for career orientation includes the following interconnected components:

1) Motivational component - the development of motives for choosing a profession and training in an institution of additional education of an artistic and aesthetic field;

2) Behavioural component - the development of independence, responsibility, and initiative [3;4];

3) Cognitive component - the development of knowledge about professions in the field of visual and spatial arts, initial professional art and graphic knowledge; artistic thinking, holistic visual perception, creative imagination, spatial representation;

4) Activity component - the development of initial professional graphic art skills [5;6].

The basis for the formation of career orientation adopted by us is a systematic approach, the methodological specificity of which is determined by the fact that it directs the process to disclose the integrity of the object, to identify the diverse types of communication of a complex object and reduce them into one theoretical picture $[7 ; 8 ; 11]$.

The systematic approach is revealed through such principles as the principle of openness, continuity, consistency and systematicity; the principle of unity and the optimal combination of academic and creative learning; the principle of socio-historical determination.

\section{METHOD}

The purpose for the formation of career orientation for adolescents is to gain the experience of a future profession in the field of visual and spatial arts, as a component of personal and creative development and self-development in conditions of additional education.

A comprehensive achievement of the goal is facilitated by a systematic approach, which provides for a clear structuring of the education content and requires the isolation and establishment of links between leading concepts and categories in the material being studied. This, in turn, allows us to maximize stimulate all the components of career orientation for adolescents.

A systematic approach involves the implementation of a number of principles. As a fundamental principle, we singled out the principle of openness, continuity, consistency and systematicity, which "is due to objectively existing stages of cognition, the interconnection

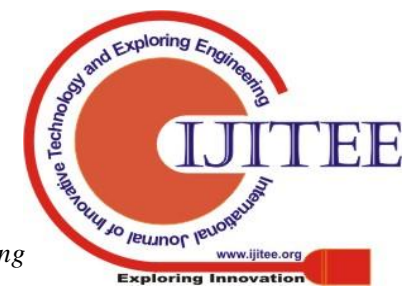


of the sensual and logical, rational and irrational, conscious and unconscious" [9, 10, 12,13].

The transition of knowledge from a simple step to a more complex one is a natural development process, the violation of which leads to unconscious actions and superficial knowledge and, therefore, inhibition of the development process. Openness is designed to give adolescents a wider range of impressions, new knowledge, and various emotions related to career guidance by enriching the process with various game techniques, design tasks that allow teenagers to fully express themselves [14].

The continuity of the education content, the consistency and systematicity in the formation of the career orientation of adolescents allows us to resolve the contradictions between the need to form a system of relevant initial professional graphic knowledge and skills, mental processes, personal and behavioural qualities, and the formation of a holistic conceptual vision of the world.

The following principle contributing to the implementation of a systematic approach to the formation of career orientation is the principle of unity of the optimal combination of academic and creative training. The creative process requires a certain reserve of knowledge of the academic art school and the experience of artistic and visual activity which determines the combination of tasks that require the use of reproductive artistic actions, with tasks are aimed at using non-standard creative abilities.

In the context of the formation of career orientation for adolescents in the field of visual and spatial arts, academic training contributes to the development of simple performing, instrumental and artistic-expressive artistic and graphic skills of adolescents, as it offers students graphic tasks aimed at finding the unknown, requiring finding connections between the known and the unknown, the establishment of the unknown on the basis of its relations with the known. Creative training presupposes the orientation of adolescents in new situations and aims them to find the unknown on the basis of its connections with the known, and the subject must be unfamiliar with the way of acting.

The principle of a socio-historical determination also acts as a principle of a systematic approach in our study; it involves taking into account the fact that the specific historical conditions of human activity always impose certain requirements on the level of education, the upbringing of a person, and set the standard for priority development directions.

Today, the most popular are design technologies and design activities covering all spheres of human activity; it requires knowledge of the main graphic methods of visualizing and transmitting information, the breadth of the artistic worldview, allowing us to see a holistic aesthetic picture of the world in all its interconnections and interdependencies. All this should be taken into account in the educational space of institutions of additional education, in particular, in the process of setting the problem, graphic task and choosing the topic of the project. This principle is also revealed in the course of teenagers performing art projects when it is necessary to study the prerequisites for the emergence of a formulated problem. This will allow us to develop an original product design that differs from the previously created one, as well as implement it in the relevant material.

We used a set of methods during the study to confirm the effectiveness of using a systematic approach and the principles that reveal it in the context of the formation of career orientation.

To identify the problem of research, we analysed pedagogical, psychological, philosophical, and art criticism literature. So, the analysis method allowed us to determine the essence of the concept "career orientation", and also the main components of the career orientation formation process, and to define a systematic approach as the leading methodological basis for its formation. As a result of this, we developed the author's program "Fundamentals of a decorator and designer professions" based on the identified principles of a systematic approach. To test the effectiveness of using the program and the systematic approach in the context of the formation of career orientation for adolescents, we organized experimental work and applied a set of empirical methods: pedagogical observation, expert assessment method, conversation, and pedagogical experiment.

\section{RESULTS AND DISCUSSION}

We allocated a control group (CG) and an experimental group (EG) of teenage pupils of 45 people each with approximately the same level of training and performance on the basis of continuing education institutions in the Children's Art School No. 3 and the Children's Art School named after M.A. Balakirev in the city of Kazan. In accordance with such criteria as cognitive and activity-informative, we diagnosed the existing level of career orientation formation at adolescents in the $\mathrm{CG}$ and the EG groups before their including in the educational process according to the author's program "Fundamentals of a decorator and designer professions".

To diagnose the career orientation formation level for adolescents, the method of expert evaluation of educational and creative tasks was used; method of analysis of artistic, art-design educational and creative works of adolescents.

In order to diagnose the level of career guidance formation for adolescents with regard to the cognitive criterion, we conducted a series of tests aimed at studying artistic and constructive thinking, perception, and spatial representation of children "Geometric figures", "Compasses", "Squares".

Next, we diagnosed the level of career orientation of adolescents in the EG and CG by the activity-meaningful criterion, which is disclosed in three parameters: 1 . The use of performing art and graphic skills; 2 . The use of instrumental art and graphic skills; 3 . The use of artistic and expressive artistic and graphic skills. We have developed two special diagnostic tasks, involving the inclusion of adolescents in a variety of situation, which was evaluated by experts on the selected parameters.

Thus, the results of the ascertaining stage of the experiment indicate that most adolescents from EG (17 people, 38\%) and CG (18 people, 38\%) groups have their career orientation index values below the average level (Table 1). This level will not allow teenagers to further achieve success in art education. In this regard, a formative stage of the experiment was further organized, the results of which, in comparison with the data of the ascertaining stage, should confirm, within statistically significant limits, an increase in the level of career orientation formation indexes for adolescents from the EG.

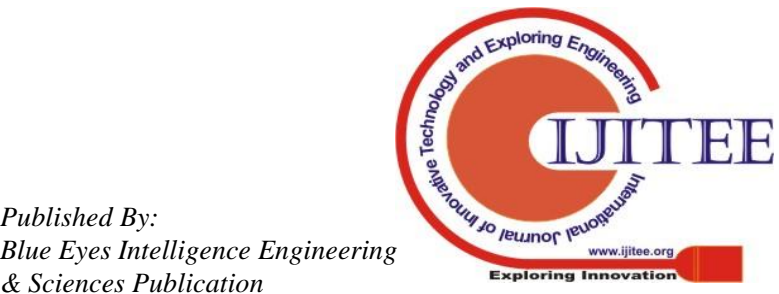


Table 1: The level of career orientation of adolescents in the EG and CG according to the results of diagnosis at an ascertaining stage

\begin{tabular}{|c|c|c|c|c|c|c|c|c|c|c|}
\hline \multirow{3}{*}{ 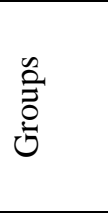 } & \multicolumn{10}{|c|}{ Levels and Points } \\
\hline & \multicolumn{2}{|c|}{ High (excellent) } & \multicolumn{2}{|c|}{$\begin{array}{c}\text { Above average } \\
\text { (optimal) }\end{array}$} & \multicolumn{2}{|c|}{ Medium (sufficient) } & \multicolumn{2}{|c|}{$\begin{array}{c}\text { Below average } \\
\text { (elementary) }\end{array}$} & \multicolumn{2}{|c|}{ Low (critical) } \\
\hline & $\begin{array}{c}\text { number of } \\
\text { pupils }\end{array}$ & $\%$ & $\begin{array}{c}\text { number of } \\
\text { pupils }\end{array}$ & $\%$ & $\begin{array}{c}\text { number of } \\
\text { pupils }\end{array}$ & $\%$ & $\begin{array}{c}\text { number of } \\
\text { pupils }\end{array}$ & $\%$ & $\begin{array}{c}\text { number of } \\
\text { pupils }\end{array}$ & $\%$ \\
\hline $\begin{array}{c}\text { EG } \\
45 \\
\text { people } \\
100 \%\end{array}$ & 0 & 0 & 2 & 4.4 & 11 & 24 & 17 & 38 & 15 & 33.3 \\
\hline $\begin{array}{c}\text { CG } \\
47 \\
\text { people } \\
100 \%\end{array}$ & 0 & 0 & 2 & 4.2 & 11 & 23,4 & 18 & 38 & 16 & 34 \\
\hline
\end{tabular}

At the formative stage, we carried out the educational process with the teenagers of the EG, involving them in the author's program "Fundamentals of a decorator and designer professions." The main goal of the formative stage was to increase the initial level of career orientation index for adolescents in the EG.

A systematic gain of artistic and graphic knowledge, skills, and artistic experience are necessary for the formation of the career orientation of adolescents in the field of art; in connection with this, the methodology of problematic presentation, the method of "brainstorming", and the obligatory regular monitoring using projective techniques were used in the classes. The noted forms and methods provided a deeper study and understanding of the content of knowledge and concepts, abilities and skills, their significance in artistic creation, their practical and creative application both in solving individual educational and creative tasks.

Upon completion of the program, we re-diagnosed the level of career orientation formation index for adolescents in the CG and EG groups using the same diagnostic methods. The index level for adolescents who receive training in the EG group increased in contrast to adolescents from the $\mathrm{CG}$ group (Table 2).

Table 2: The level of career orientation indexes for adolescents in the EG and CG groups at the control stage

\begin{tabular}{|c|c|c|c|c|c|c|c|c|c|c|}
\hline \multirow{3}{*}{ 总 } & \multicolumn{10}{|c|}{ Levels and Points } \\
\hline & \multicolumn{2}{|c|}{$\begin{array}{c}\text { High } \\
\text { (excellent) }\end{array}$} & \multicolumn{2}{|c|}{$\begin{array}{l}\text { Above average } \\
\text { (optimal) }\end{array}$} & \multicolumn{2}{|c|}{$\begin{array}{c}\text { Medium } \\
\text { (sufficient) }\end{array}$} & \multicolumn{2}{|c|}{$\begin{array}{c}\text { Below average } \\
\text { (elementary) }\end{array}$} & \multicolumn{2}{|c|}{ Low (critical) } \\
\hline & quantity & $\%$ & quantity & $\%$ & quantity & $\%$ & quantity & $\%$ & quantity & $\%$ \\
\hline $\begin{array}{c}\text { EG } \\
45 \\
\text { people } \\
\end{array}$ & 5 & 11 & 30 & 67 & 7 & 16 & 3 & 7 & 0 & 0 \\
\hline $\begin{array}{c}\text { CG } \\
47 \\
\text { people }\end{array}$ & 0 & 0 & 15 & 32 & 15 & 32 & 14 & 30 & 3 & 6 \\
\hline
\end{tabular}

\section{IV.SUMMARY}

Diagnosis indicates an increase in the level of career orientation formation in adolescents of the experimental group (EG). Such results are due to the fact that experimental work had the greatest impact on the formation of the whole complex of components of career orientation. Adolescents more actively began to show initiative and independence, a systematic approach and its principles implemented through the author's program, and also contributed to gaining skills of a responsible attitude to work. Teenagers got acquainted with the algorithms and the specifics of the professional activities of a decorator and a designer. The participants in the experiment with desire and consciously approached the execution of sketches, brief sketches, sketch ideas, made cardboard which was then embodied in real object models and more complex objects (layouts, household items, etc.). The readiness of adolescents from the EG to reflect the idea through modern computer technologies has significantly increased and their degree of independence in the selection and use of art materials, techniques and their combinations in accordance with the plot and design task has also increased. Most teenagers in the EG (26 people, or 58\%) competently structured preliminary work on sketching, variably searched for original ideas using graphics, created an expressive composition and original artistic images, actively used previously acquired knowledge, skills in performing creative tasks, and also projects in non-standard art-graphic situations.

As a result of the experimental work, significant changes were achieved in adolescents from the $E G$ in relation to interpersonal communication, and also to themselves as to 
subjects of creativity. With an increase in the level of career orientation, a need arose for the development of their artistic and graphic skills, and also to artistic literacy as a whole, necessary for their future profession.

\section{CONCLUSIONS}

Thus, the experimental work, including the ascertaining, formative and control stages, allows us to conclude that the significant positive dynamics that occurred in adolescents of the experimental group should be considered a criterion for the effectiveness and appropriateness of this work which provides a high level of formation of career orientation.

The dynamics mentioned above was found in their progressive transformation of qualitative and quantitative indicators of artistic thinking, holistic visual perception, spatial representation, creative imagination, artistic and graphic knowledge, skills, and were reflected in the complication and growth of levels. These results confirm the effectiveness of using a systematic approach, as well as the principle of openness, continuity, consistency and systematicity; the principle of unity and the optimal combination of academic and creative learning; and also the principle of socio-historical determination. These approaches and principles have become the methodological basis of our program "Fundamentals of a decorator and a designer profession".

The result of the work was the formation of career orientation of adolescents; systematic development of initial professional graphic art knowledge, skills; the formation of significant personality traits, such as independence, initiative, responsibility, and the gain of diverse experience in art and design activities.

\section{ACKNOWLEDGEMENTS}

The work is performed according to the Russian Government Program of Competitive Growth of Kazan Federal University.

\section{REFERENCES}

1. Roccas, S. The big five personality factors and personal values /S Roccas, L. Sagiv, S.H. Schwartz, A. Knafo// Personality and Social Psychology Bulletin. - 2002. - № 28. - P. 189-201.

2. Kosaretsky, S. Specific Features of Children Involvement in Supplementary Education Depending on Cultural, Educational and Financial Status of Families and Place of Living / S. Kosaretsky, B. Kupriyanov, D. Filippova // Educational studies. - 2016. - № 1. P. 168-190.

3. Akbariva, G.N. The development of readiness of teenagers to the project activity by means of fine arts / G.N. Akbariva, L.P. Yephimova, Z. M. Yavgildina // Social Sciences (Pakistan), 2015. - 10 (5), pp. 639-645.

4. Akhmetshina E. G. Pedagogical approaches to the development system of the artistic culture of individual / E.G. Akhmetshina, L. H. Kadyjrova // Revista san gregorio. - 2017. - №20 (special edition, December) ISSN: 1390-7247; eISSN: 2528-7907. - P.189-193

5. Valeeva, R.A. Distance learning for aesthetic education - Informed professional development and life-long learning of student teachers / R.A. Valeeva, S.V. Karkina, A.I. Starcic //ACM International Conference Proceeding Series. - 2018. - Vol. 2 - P.597-603.

6. Salakhov R.F, Esthetic education of children with special needs by means of computer art / R.F. Salakhov, R.I. Salakhova, R.R. Nasibullov // International Journal of Environmental and Science Education. - 2016. - Vol. 11, Is.6, P. 1137-1148.

7. Afanasyev, V.G. Society, systematicity, cognition, management [Text] / V.G. Afanasyev. - M.: Politizdat, 1981. - 250 p.

8. Uemov, A.I. System approach and the general theory of systems [Text] / A.I. Uemov. - M.: Thought, 1978. - 272 p.
9. Bespalko, V.P. Components of educational technology [Text] / V.P. Pespalko. - M.: Pedagogy, 1989. -- 190 p.

10. Slastenin, V.A. Pedagogy [Text]: a textbook for pupils of higher educational institutions / V.A. Slastenin, I.F. Isaev, E.N. Shiyanov; edited by V.A. Slenin. - 6th edition, stereotyped. - M.: Publishing Centre "Academy", 2007. - 576 p.

11. Mardani, M., \& Fallah, R. Comparison of Financial Leverage Ratio before and after the Use of Off-Balance Sheet Financing in Firms Listed in the Tehran Stock Exchange. Dutch Journal of Finance and Management, 2(2), (2018). 53. https://doi.org/10.29333/djfm/5829

12. Dominguez, L., D’Amato, J. P., Perez, A., Rubiales, A., \& Barbuzza, R. A GPU-Accelerated LPR Algorithm on Broad Vision Survillance Cameras. Journal of Information Systems Engineering \& Management, 3(3), (2018). 24.

13. Ulandari, L., Amry, Z., \& Saragih, S. Development of Learning Materials Based on Realistic Mathematics Education Approach to Improve Students' Mathematical Problem Solving Ability and Self-Efficacy. International Electronic Journal of Mathematics Education, $\quad$ 14(2), 375-383 https://doi.org/10.29333/iejme/5721

14. Nebessayeva, Z., Bekbolatova, K., Mussakulov, K., Zhanbirshiyev, S., $\&$ Tulepov, L. Promotion of entrepreneurship development by art and design by pedagogy. Opción, 34(85-2), (2018). 729-751. 